2006-2645: TECHNOLOGY ASSISTED SCIENCE, ENGINEERING AND

MATHEMATICS (TASEM) EDUCATION AT ALL LEVELS USING K-PH.D. CONCEPT

Dean Aslam, Michigan State University 


\section{Technology Assisted Science, Engineering and Mathematics Education at all Levels using K-Ph.D. Concept}

\section{Introduction}

Although United States is the world leader in a number of technological innovations, other countries are increasingly challenging this leadership by introducing science, technology, engineering and mathematics (STEM) education with greater depth of knowledge at the grass root level (elementary and middle schools). For example, in contrast to the emphasis on earth and bio sciences in the US elementary and middle schools, more emphasis on the physics teaching in elementary and middle schools in some Asian countries may be related to high math and science scores in those countries. Whether this is an indication that an early physics education enhances logical thinking boosting math skills seems logical but needs to be investigated.

Traditionally, school science has been built around well defined problems, mostly involving topdown approaches where the decisions on learning methods are made by educational experts and organizations. In the real world, however, the problems are not well defined and clear-cut decisions on the best learning modules are very difficult. Consequently, a restructuring of school science around real-world problems has been suggested by educational experts and organizations ${ }^{1-3}$, which has led to a number of studies focusing on inquiry ${ }^{4-7}$. Notable examples of inquiry based studies are Design-Based Science $(\mathrm{DBS})^{8-17}$ and Learning By Design (LBD) $)^{18-20}$.

It is surprising that, in spite of all these learning techniques and presence of multi-million NSFfunded learning centers, math and scores are not improving as expected. This may be, in part, due to the hesitation of state boards and teachers to follow innovative paths of learning developed in the educational cemters. Recently, new learning techniques have focused on the use of technology that sparks the interest of children. A learning technique may be approved by educational experts and organizations but if it does not spark the interest of children, its efficacy may be questionable. A further development of the Design concept has benefited from virtual reality (VR) and augmented reality $(\mathrm{AR})^{21-27}$, the later combines real and virtual worlds. Studies have suggested that, through the use of AR, spatial abilities can be improved ${ }^{22-23}$. VR/AR can also help explain complex concepts, devices and systems in an interesting manner. For example, using characters from popular animated films, such as Bug's Life, to explain complex concepts of math and science can substantially raise the interest of the children.

This work reports on an innovative Technology Assisted Science, Engineering and Mathematics (TASEM) education program that has been developed in collaboration with and participation of K-12 students and teachers ${ }^{28-29}$. As TASEM focuses on the interest and excitement level of the learner, it has sparked interest of over $600 \mathrm{~K}-12$ students in last two years alone in Macomb and Oakland counties of Michigan. Using an environment, called from kindergarten to Ph.D. or K-Ph.D., graduate students involved in cutting-edge micro and nano technologies act as role models for the learner. Starting with examples of things that the learner is already familiar with, TASEM takes them on an exciting journey into the unknown. The first phase of the TASEM program has focused mainly on the development and use of technology in K-12 education. The understanding of micro and nano dimensions can help understand the role of technology in making micro-devices and -systems.

\section{Micro and Nano Dimensions and Related Technologies}

As in the current work the technology is used as vehicle to teach Science, Engineering and 


\section{Figure 1}

HOW SMALL IS

A MICROMETER?

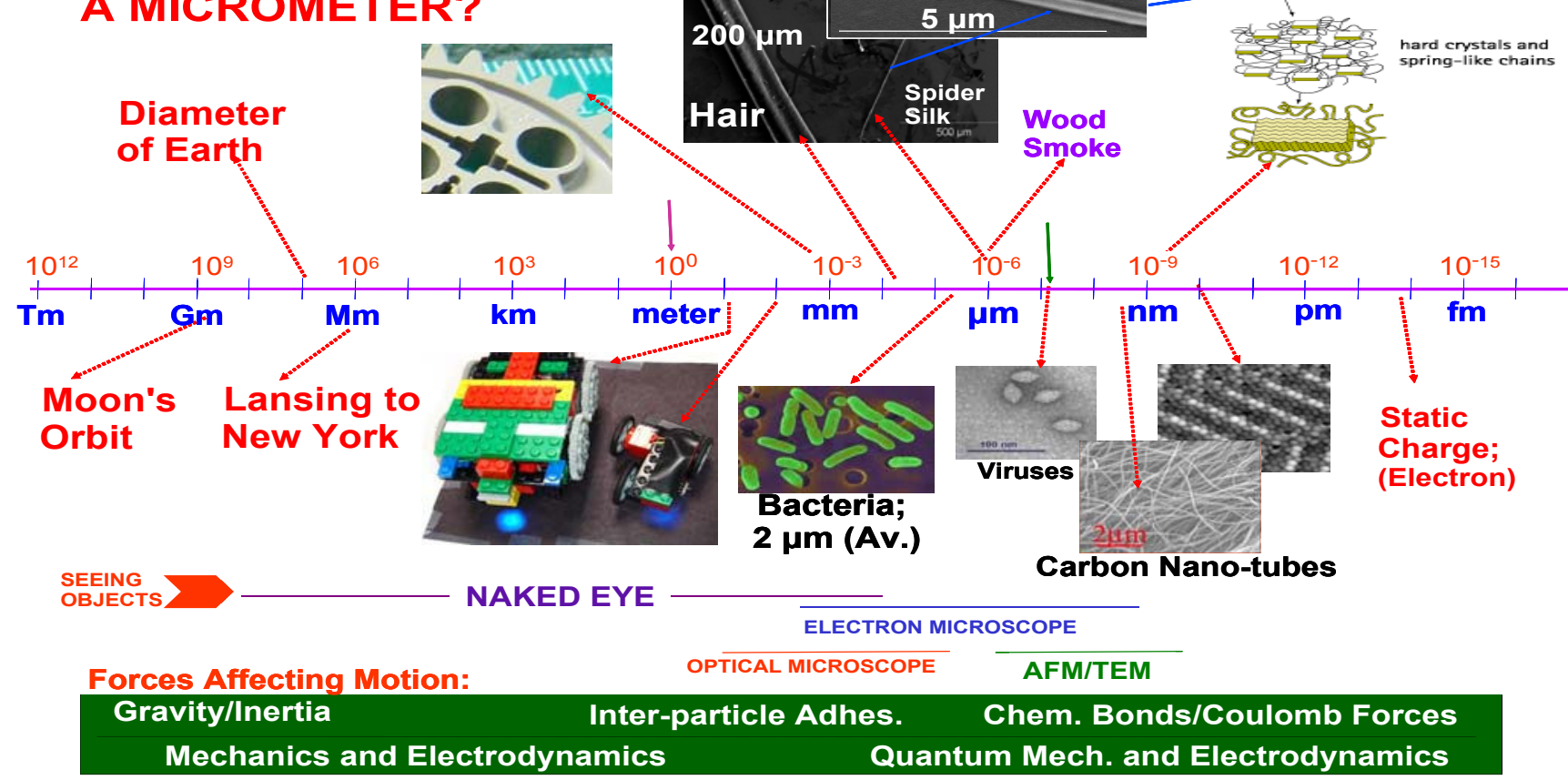

Mathematics (SEM), an important basic task is to develop techniques that help explain miniaturization of dimensions leading to nanotechnology. As shown in Figure 1, there are $1000 \mathrm{~mm}$ in a meter, 1000 micrometers $(\mathrm{m})$ in a $\mathrm{mm}, 1000$ nanometers $(\mathrm{nm})$ in a $\mathrm{m}$ and 1000 picometers $(\mathrm{pm})$ in a $\mathrm{nm}$. A single strand of spider silk, or a smoke particle, is approximately $1 \mathrm{~m}$ in diameter. As most children know that one needs a microscope to see small objects, they would like to know if they can use an optical microscope to see nanometer size objects (Fig. 1). If not, how can one explain to children how an Atomic Force Microscope (AFM) or a Transmission Electron Microscope (TEM) works? This is important because AFM and TEM can help see nano-structures or even atoms.

A concept of a Toy Force Microscope (TFM) was developed to explain the principle of operation of an AFM. As shown in Figure 2, the first version of this TFM was built using Lego pieces. A long beam was hinged using a stable anchor. The free end of a fine needle, attached to one end of the beam, moves on a rough surface to be pictured. As the beam moves in horizontal plane parallel to the rough surface the needle moves up and down. Near the end of the other arm of the beam, which is substantially longer than the one with the needle, a toy LASER is attached. The LASER beam, after multiple reflections from the mirrors, falls on a white wall. As expected, the up and down movement of the needle is magnified on the wall. We were able to magnify it by a factor of at least 10 using

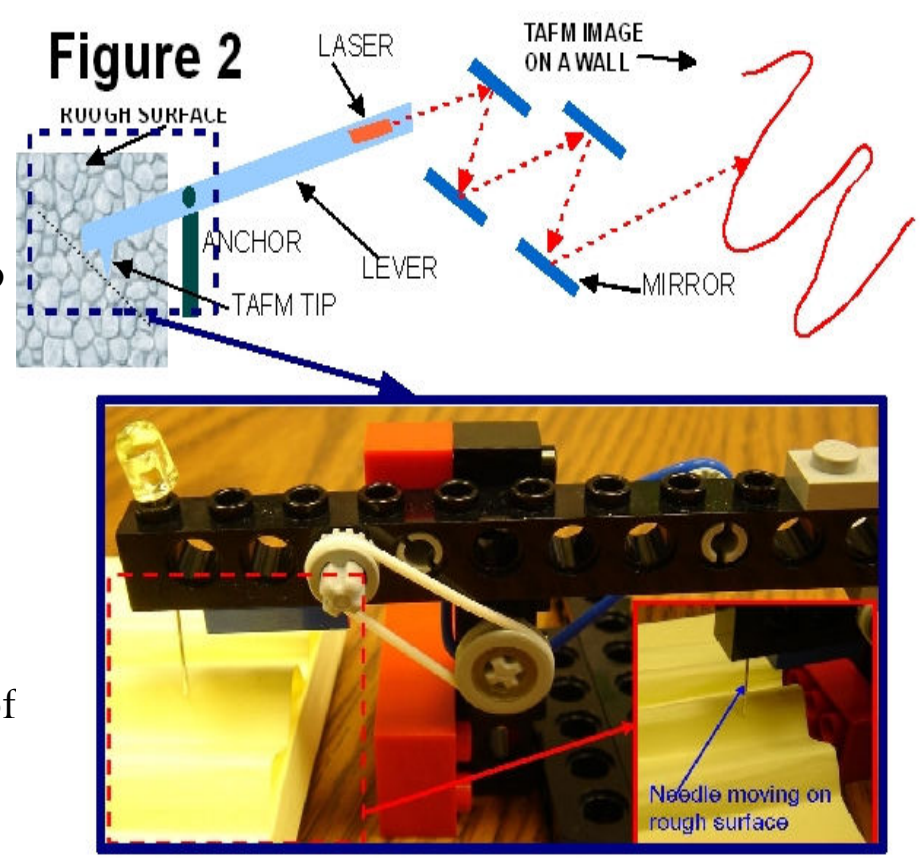


the Lego based TFM. A more sophisticated version of such a TFM, if build with precise mechanical parts, can lead to a substantially higher resolution. This simple construction explains the actual principle of an AFM, which can then be shown to children in an arranged visit to an AFM facility. We have tested this concept on a number of children in grades 4-8 and they seem to get some idea of how an AFM works on the nanoscale. However, one needs to do a systematic study on a larger number of children with the help of teachers and educational experts, which will be the subject of a subsequent study.

\section{Science, Engineering and Mathematics}

Now we are ready to explain some science and engineering principles. A Pentium 4 microprocessor has millions of transistors integrated on an area of approximately $1-2 \mathrm{~cm}^{2}$. The use of a transistor as a switch is a key concept in today's computer systems. What is a transistor and how does it work as a switch? How can millions of transistors can be integrated on a small area? If a transistor is made so small, possibly with nanometer dimensions, can it still function as a switch? While the answers to these questions may be obvious to researchers in the filed, to answer these questions for K-12 children, keeping their interest and excitement level high, is definitely a daunting challenge.

Such questions have been crossing the minds of many educators including 3 teachers from Okemos High School (OHS) in Michigan. A very intriguing suggestion was made by these 3 science teachers. They said that if one can fabricate a big (millimeter size) transistor such that the children can see its structure with a naked eye, and perhaps do some measurements on it, one can explain how Pentium microprocessors are made. Our TASEM team took this as a challenge and designed, with participation of two seniors from Okemos High (Greg Wile and Jonathan Brown), a K-12 chip shown in Figure 3. The chip was then fabricated at University of Michigan's microfabrication facility under supervision by Prof. Wise. The chip was mounted on the breadboard shown on the Lego chip in Figure 3(on the left side of the breadboard). This chip also had logic gates and a ring oscillator. The MOSFET characteristics were measured by the high school students supervised by Ph.D. students.

The work on K-12 chip revealed a bigger challenge, for the TASEM team, of explaining the fabrication and operation of a MOSFET to the K-12 students in way that is simple and exciting.

An NMOS (n-channel MOSFET) was selected for explaining the transistor concepts. Fig. 3 shows a Lego-based demo testchip along with 2 demos for NMOS assuming micro and nano sizes. NMOS devices.

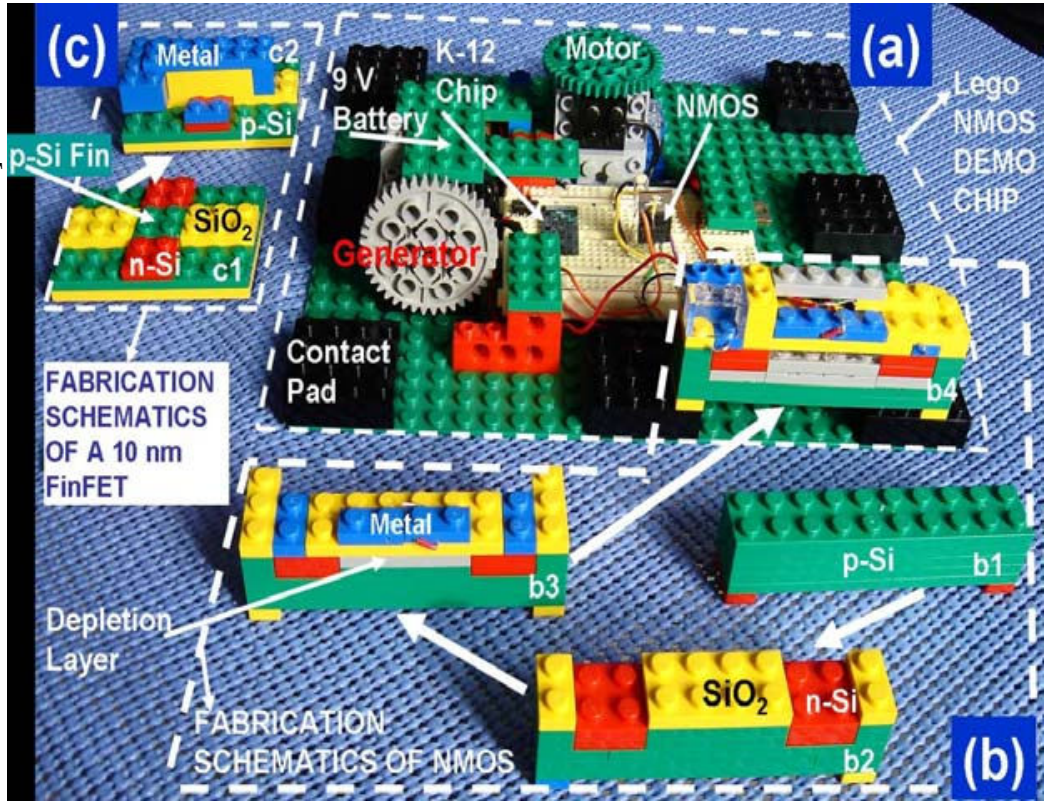

Figure 3 NMOS demo chip overview (a) and explanation of fabrication and principle of operation of micro (b) and nano (c) In addition to a number Lego pieces, there are two motors, a breadboard, a K-12 chip, and a number of other electronic devices on the demo chip. 
Fig. 3(a) shows a layout of a Lego demo chip with a chip size of approximately $370 \mathrm{~cm}^{2}(7.2$ " $\mathrm{x}$ 7.8'), the contact pads are shown in black. A 9 V battery, embedded near the upper left side of the chip, supplies power for all devices shown in Figure 3; 2 NMOS transistors (IRF531), a Lego motor and 5 light emitting diodes (LED). Only the gate voltage is supplied by the second Lego motor (generator). One of the NMOS devices is embedded into Lego construction b4 located near lower right side of the demo chip.

As shown in Fig. 3(b), a fabrication process sequence, simplified using Lego pieces, depicts 4 cross-sectional views, b1b4, of the NMOS. P-type Si is represented by green Lego plates. Red areas are n-Si and are called source (S) and drain (D). S/D regions, in an actual Si microfabrication process, are created by introducing n-type impurities (such as phosphorous) into a $\mathrm{p}-\mathrm{Si}$ wafer using silicon dioxide $\left(\mathrm{SiO}_{2}\right)$ as a diffusion mask. This is possible because the diffusion constant of phosphorous in $\mathrm{SiO}_{2}$ is very low as compared to that in $\mathrm{Si}$. Thus, the presence of $\mathrm{SiO}_{2}$ makes sure that the n-type impurities are introduced in red areas (S/D) only. Following the thick white arrows (see b1 through b4), the next step is to make metal contacts (blue plates) to form $\mathrm{S} / \mathrm{D}$ leads.

The structure b4 contains a complete circuit connecting S and D to a blue LED and a $9 \mathrm{~V}$ supply voltage. Fig. 4 elaborates further the operation of the NMOS switch. From Fig. 4(a) it may be noticed that there is no channel because the gate voltage $V_{G}$ is not high enough. However, as shown in Fig. (b), a high enough gate voltage is applied by turning a Lego motor clockwise. The channel appears typically at $5 \mathrm{~V}$ and the blue LED lights up. The visualization of the red channel region was accomplished by mounting tiny red LEDs in the Lego plates representing the channel region.

The children and teachers (including some MSU professors) who saw this demonstration of the use of an NMOS as a switch were impressed by the fact the switched could be turned on by rotationg the motor clockwise and turned off by rotating the motor
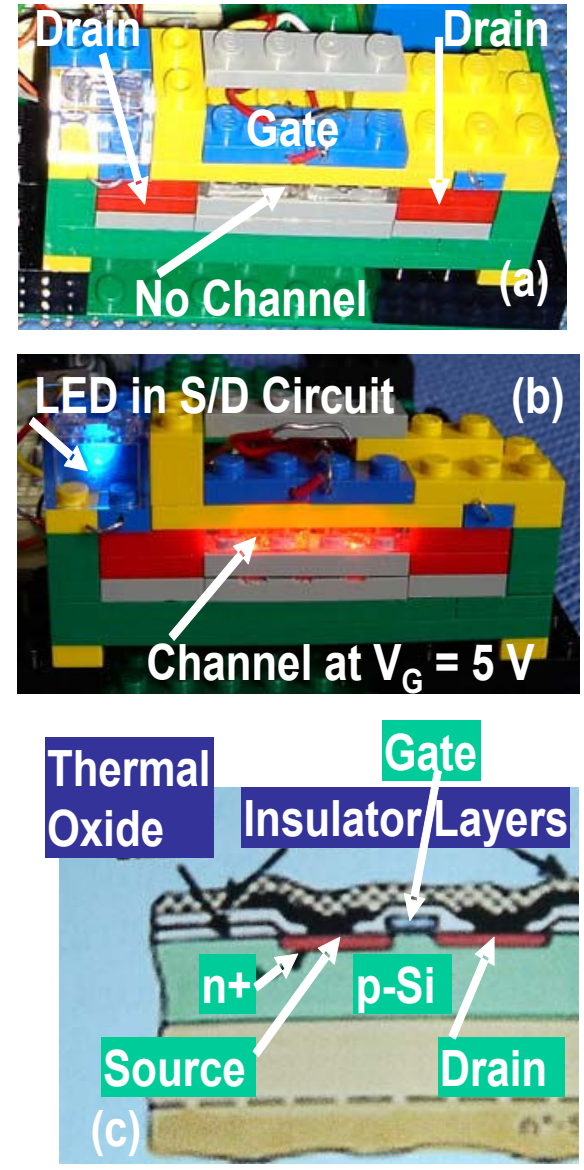

Fig. 4 NMOS realized in Lego pieces; (a) gate voltage, $\mathrm{V}_{\mathrm{G}}$ not enough to create channel, (b) channel is created at $\mathrm{V}_{\mathrm{G}}>4 \mathrm{~V}$ and (c) a typical schematic of $\mathrm{NMOS}^{30}$ anti-clockwise (or by connecting the gate to zero). Interestingly, the

NMOS could be turned off by the static accumulated on a comb after combing the hair. Of course, too much static charge can also destroy the NMOS. The children were fascinated by the usefulness of static charge, which they are so familiar with inside a heated home after they walk on a carpet. This demo is a very interesting way to introduce the electronic circuit concept to children at an early stage (parts of the demo are suitable for $4-8$ graders).

For comparison, Fig. 4(c) shows a typical NMOS cross-sectional view found in text books ${ }^{30}$. It may be pointed out that a circuit containing NMOS and PMOS together is called complimentary MOS (CMOS), which is the latest technology used in Pentium processors. While the current S to D separation, the channel length, in Pentium processors is in the range of $65-95 \mathrm{~nm}$, the future channel lengths are expected to be decreased down to mere $10 \mathrm{~nm}$. Such NMOS transistors, the so called nanoNMOS, have different geometries than those shown in Fig. 4 (b). 
Fig. 4 (c) shows a Lego version of a nanoNMOS, called FinFET, in which a Si fin is created using dry etching of Si (see c1 in Fig. 4). Although, Fig. 4(c:c2) shows a completed but very simplified structure of a FinFET, it is a very simple way to visualize the actual FinFET structure details as shown in Fig. 5. There are a number of studies focusing on reducing the dimensions of CMOS devices ${ }^{31}$. The smallest reported Si device is a $10 \mathrm{~nm} \mathrm{FinFET}^{32}$.

To further address the issue of a nanometer size devices, a second generation of the K-12 chip was fabricated. It had metal lines for making nanosensors for chemical detection. Carbon nanotubes (CNT)
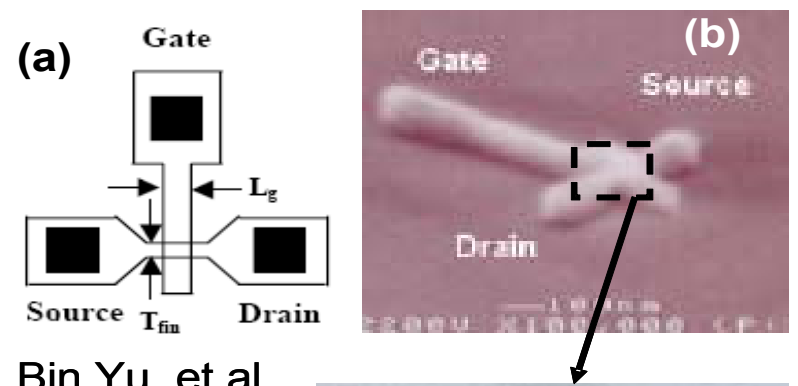

Bin Yu, et al., UC Berkeley, IEEE 2002

Figure $5 \mathrm{~A}$ schematic (a) and actual FinFET (b-c).

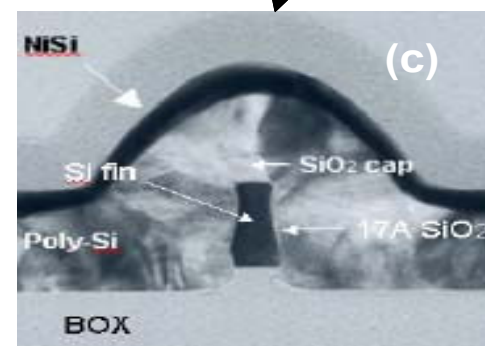
were randomly scattered on these metal lines to fabricate CNT nanoresistors. These are shown in Figure 6. A TEM picture of a multiwall CNT is also shown, in which each wall layer is made of carbon hexagons. The bond length between carbon atoms in these hexagons is approximately $140 \mathrm{pm}$ or $0.14 \mathrm{~nm}$. An animation of a single wall CNT is also shown to the children. The devices shown in Figure 3 start with dimensions that are large enough that children can put their hand on and play. The TASEM team can then take the children on a journey into the unseen world of nano and pico dimensions with the help of concepts depicted in Fig. 6.

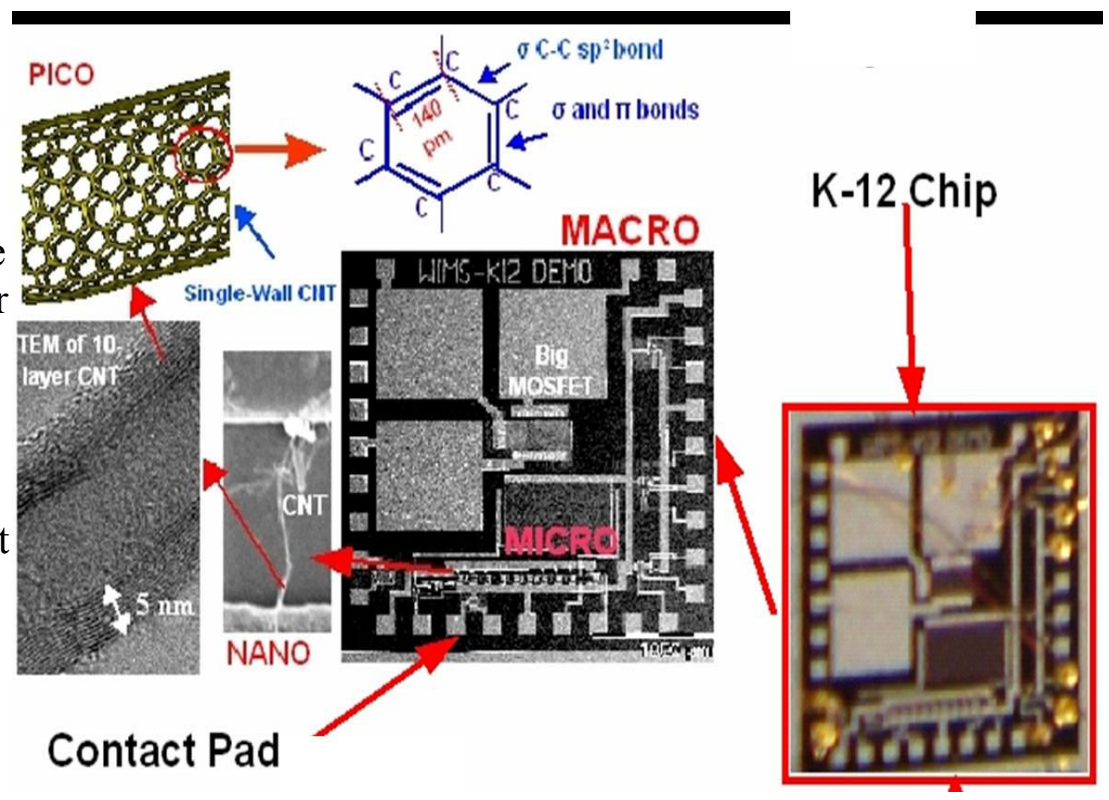
Children's remarkable imagination and curiosity facilitates this journey.

Figure 6 Nanosensors fabricated on K-12 chip using carbon nanotubes.

Another system we built using Lego pieces is a wireless system containing motors, LEDs, an optical bench, a position sensor, an RPM meter and a Lego flash light as shown in Figure 7. It has 3 nodes with inter-node wireless connection using visible light. The node 1 is just a flash light. The node 2 has an embedded circuit built using Al foil interconnects between circuit components, which include a battery, a motor, an LED and a photoresistor all connected in series. If the photoresistor receives no light, the circuit is off because the resistance of the photoresistor is too high for an appreciable current to exist in the

Figure 7 A wireless Lego-based microsystem.

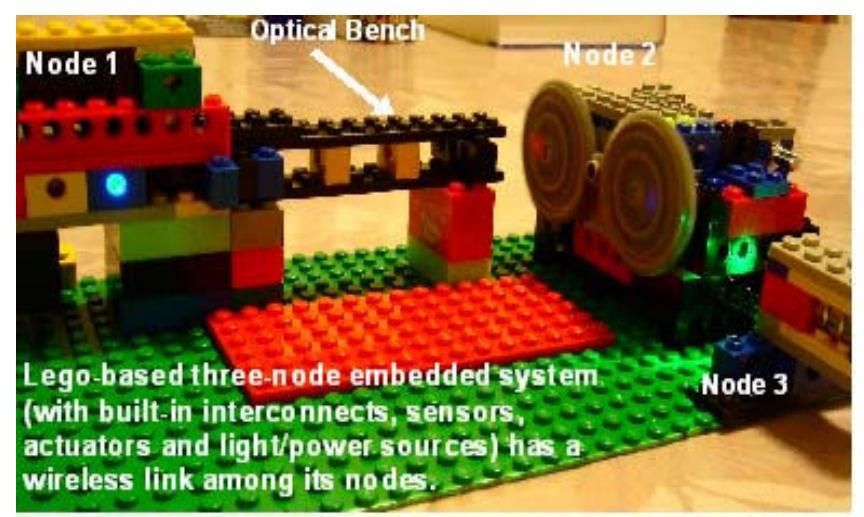


circuit. If the photoresistor is exposed to light, the Lego motor drives two large gears with holes. One of the gears has all holes blocked except one. Light from an LED, mounted behind this gear, escapes through the open hole once per gear rotation and is guided through an optical bench to the circuit in node 3 . The circuit in node 3 consists of a blue LED, a battery and a photoresistor. The blinking of the blue LED is a measure of the RPM of the gear. The children love this system but may not realize how much they learn when they play with this system.

In other experiments TASEM focuses on the use of a programmable robot called Robotic Invention System (RIS) by Mindstorm. A very interesting example of how much excitement this robot can create is a card sorter robot designed, built and programmed by a second grader (Figure 8). A motor is run by the RIS to move a black belt in one direction. A light sensor with a built-in light source is mounted above the belt. If a black card is placed on the belt the sensor detects no reflected light and the card is thrown in the basket in the front (see Figure 8). However, when a white card is placed on the belt, the sensor receives the reflected light and the RIS is programmed to reverse the motor for 1.5 seconds. Thus, the card is thrown in the rear basket.

The RIS was also used to study Newton's laws in a number of experiments (see a sample of a manual for one such experiment in Appendix A). The experiments include distance measurement (Figure 9), velocity measurement, acceleration measurement, value of gravitation constant, spring constant, etc. A rotation sensor attached to one of the wheels of the robot is used for distance measurement.

The RIS can be used to measure the area of a circle, a triangle or a shape made of right angle triangles. In these experiments, a circle or a right angle triangle is made on a white paper using black lines (see Fig. 10). The robot is programmed to follow a line with the help of a light sensor. As it moves along the black line, it measures the length of the lines, from which it calculates the area using mathematical expressions for area. Fig. 10 (b) shows this experiment using a microcontroller based robot built at MSU.

In a number of experiments, involving a higher level of learning, the microcontrollers are used to built robot inspired learning systems (RILS) and microsensor inspired learning systems (MILS). Figure 11 shows two examples of RILS built by the TASEM teams. The robots shown in Figure 11 are used to demonstrate the concept of miniaturization of robots. This helps to explain how

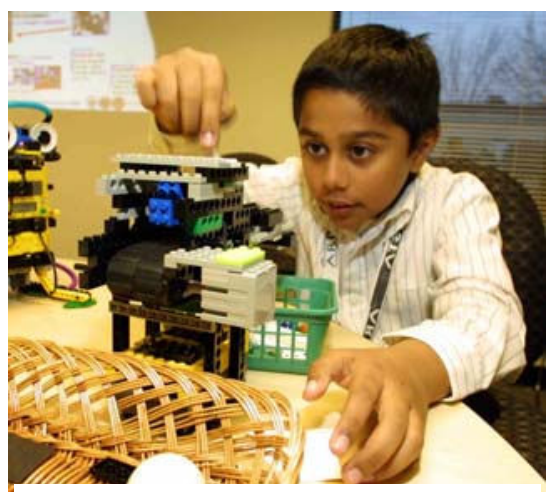

Fig. 8 Shawn is presenting his invention at the Ardesta openhouse in December 2001 in Ann arbor; the invention led to a donation of $\$ 1,000$ to his school.

Figure 9 Distance measurement using a light sensor.
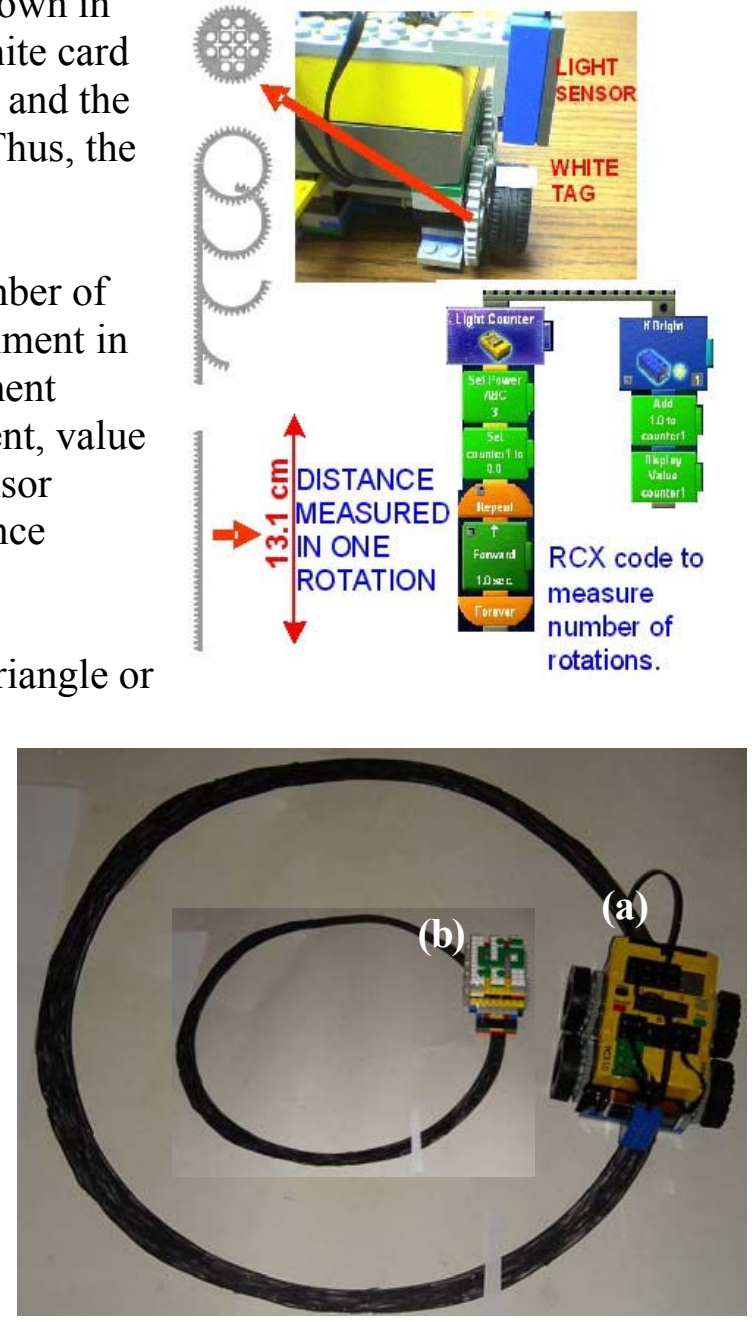

Figure 10 Area of a circle measured by RIS (a) or MSU Smart-Robot (b). 
miniature robots are being used to image the human digestive track because the robotic devices have on-board video camera and other micro-instruments.

Such robots are programmable in $\mathrm{C}$ and are expected to be marketed for under $\$ 50$ by the TASEM teams. A unique feature of the MSU smart robot is its user-upgradeable capability and its larger number of programmable motor and sensor ports (than for example the RIS). The user can even upgrade the microcontroller, which is not possible for any robot in its price class. A wall-climber, robots; miniaturization. completed in Summer 2005, is shown in Fig. 12. Plans for its commercialization are under way (the target price is $\$ 200$ ).

Other examples of MILS and RILS are shown in Figures 13-15. An environmental monitor, shown in Figure 13, is based on a PIC 16F876 microcontroller and can measure air temperature, density, pressure change and speed. This monitor was designed, tested and packaged by the TASEM teams.

A module developed for Okemos High teachers can monitor a chemical reaction (Figure 14). It is being used in a class room by $\mathrm{Mr}$. Carrier of Okemos High in addition to another module which can

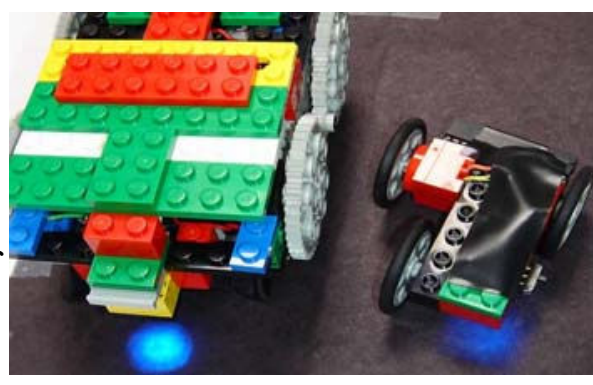

Figure 11 Microcontroller based

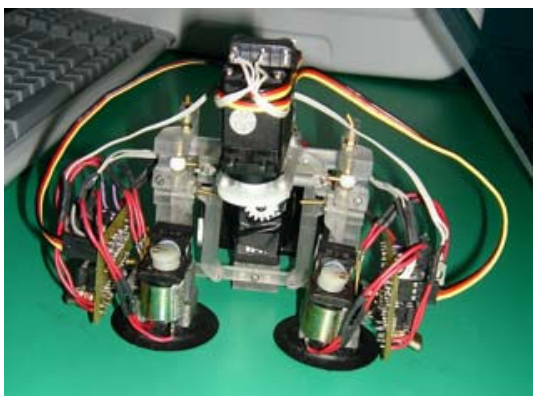

Figure 12 Microcontroller

based wall-clamber robot. measure magnetic field using a Hall sensor. A number of other exciting modules were also developed (Figure 15) and will be described in future reports. Some of these modules are built using PIC microcontrollers. An easy to use manual for microcontroller programming was developed, especially for middle and high school students. A copy of this manual is provided in Appendix B.

An interesting feature of the TASEM modules is the

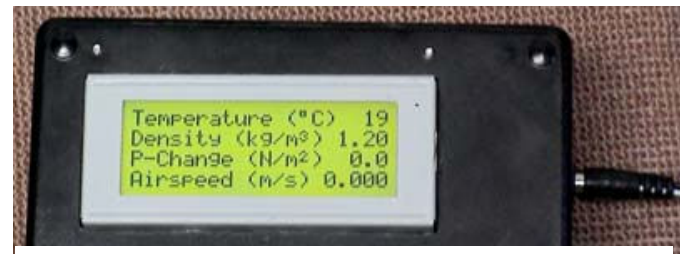

Fig. 13 Environmental monitor prototype built by Nathan Usher, an MSU undergraduate. development of low-cost learning modules shown in Fig. 16.

These modules are used for children in grades pre-K through 3. Some of these modules use capacitor batteries. Capacitors with capacitances in the range of $0.5-5$ Farads are equipped with safety features by the TASEM teams so that the children do not misuse the capacitors. For example, such high-capacity capacitors must be connected with proper polarity (positive to positive and negative to negative) when charging them. The children charge the capacitors using Lego motors, which can generate voltages in access of 15 volts if a gear combination is used to make the motor axle run very fast (children love to drive them at maximum speeds). To make sure that the charging voltages do not exceed the rated values on the capacitors, a Zener diode is connected in parallel with a capacitor. The diode also protects the capacitors if the motor turning in the wrong direction provides a voltage of wrong polarity to the capacitor. In this case, the Zener diode is forward biased and the motor current is directed through the lowest resistance path, which is the forward biased diode and not the capacitor. Finally, for commercialization, the capacitor can be packaged in a secure housing.

Fig. 14 WIMS chemical reaction monitor built by Greg Wile of Okemos High.

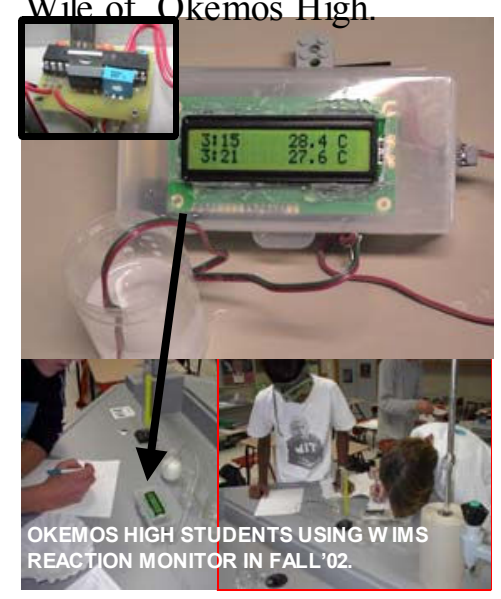




\section{Field Testing and Tracking}

The K-12 students who used MSU's MANTL Lab have been very successful as seen in Table 1 . The TASEM modules have been field-tested in Summer Camps, in- and after-schools sessions, sessions offered to home-schooling groups and science teacher workshops in Ingham and Oakland counties in Michigan during 2000-2005. For remote locations, live video sessions are used for direct interactions of TASEM faculty with children while the TASEM instructors normally go on-site and interact with teachers and students.

TASEM teams design simple tests to check the level of understanding of the participants. Such tests and procedure are prepared in consultations with teachers. One particularly interesting learning manual is the one prepared for children in grades pre-K through 2. The children learn in four 30 minutes segments requiring $100 \%$ instructor presence. Specially designed low-cost Lego modules have been developed for small children (Figure 16). For early grades, the low-cost modules are used before they can interact with a programmable RIS or other robots. Three detailed manuals have been developed to accompany the modules in a session.

The popularity of the TASEM program is indicated by the fact that, during the last 2 years alone, over 600 children in grades pre-K through 12 have participated in local as well as Internet based sessions organized by the TASEM teams. In all sessions, which provide a notebook PC, RIS set, microcontroller programming system and other
Figure 15 TASEM learning modules prepared using RIS or microcontrollers will the subject of subsequent publications.

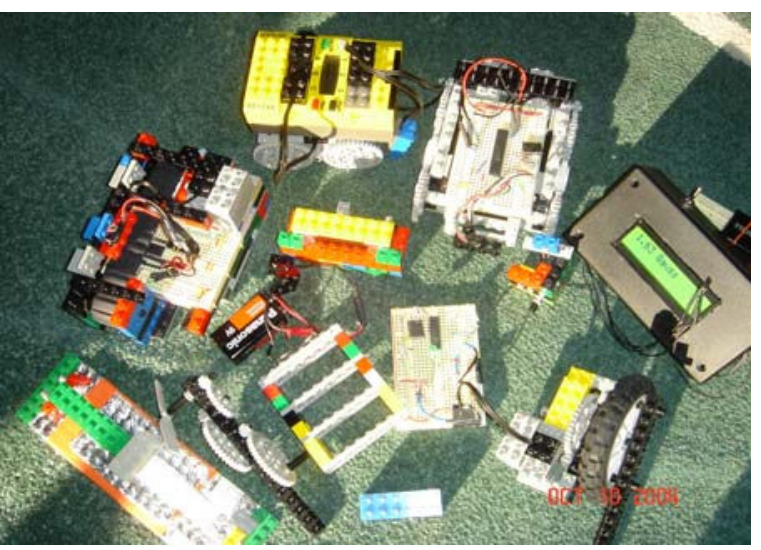

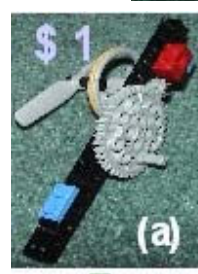
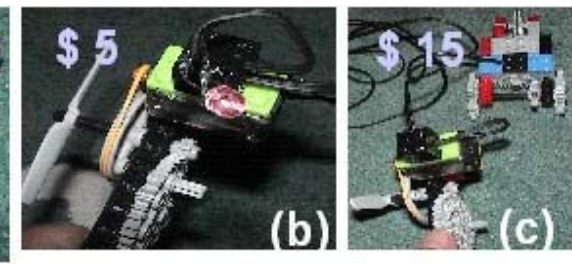

Energy generation \& conversion:

Motion, gears and torque, a motor as generator, energy conversion, engineering

Figure 16 Low-cost modules.
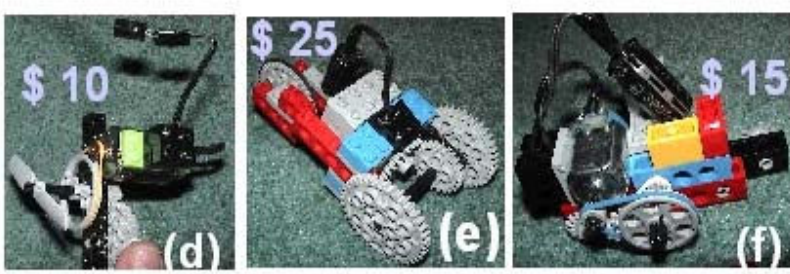

Energy storage \& usage:

Energy storage, capacitor, technology, physics, electrical \& mechanical engineering

\begin{tabular}{|c|c|c|c|c|}
\hline UG Student & Area of Activity & $\begin{array}{l}\text { Worked in } \\
\text { MANTL }\end{array}$ & School & Study At \\
\hline Greg Wile & $\begin{array}{l}\text { Study science/techn/math by } \\
\text { programmable robots }\end{array}$ & $2000-03$ & Okemos High & Case Western \\
\hline $\begin{array}{l}\text { Jonathan } \\
\text { Brown }\end{array}$ & $\begin{array}{l}\text { Study science/techn/math by } \\
\text { programmable robots }\end{array}$ & $2000-03$ & Okemos High & U. of Michigan \\
\hline Tania Yusaf & $\begin{array}{l}\text { Science/techn/math } \\
\text { programmable robotic doll }\end{array}$ & $2001-03$ & Okemos High & MSU \\
\hline $\begin{array}{l}\text { Michael } \\
\text { Offenberg }\end{array}$ & $\begin{array}{l}\text { Study science/techn/math by } \\
\text { programmable robots }\end{array}$ & $1999-2003$ & Okemos High & U. of Michigan \\
\hline $\begin{array}{l}\text { Brandon } \\
\text { Gregory }\end{array}$ & $\begin{array}{l}\text { Study science/techn } / \text { math by } \\
\text { programmable robots }\end{array}$ & $1998-2002$ & Okemos High & U. of Michigan \\
\hline $\begin{array}{l}\text { Gaurav } \\
\text { Bhatnagar }\end{array}$ & $\begin{array}{l}\text { Study science/techn/math by } \\
\text { programmable robots }\end{array}$ & $1998-2002$ & Okemos High & U. of Michigan \\
\hline Shaili Jain & Programmable robots & $1998-2000$ & Okemos High & $\begin{array}{l}\text { Havard } \\
\text { University }\end{array}$ \\
\hline Chris Loose & Microfabrication & $1996-97$ & Okemos High & $\begin{array}{l}\text { Princeton } \\
\text { University }\end{array}$ \\
\hline Shong ... & Microfabrication & Summer 1995 & $\begin{array}{l}\text { A school in New } \\
\text { York area }\end{array}$ & UC Berkeley \\
\hline
\end{tabular}


components for every station, the number of participants is limited not by interest but the number of stations that can be provided. We could have served a substantially higher number of children, had we more stations.

\section{Acknowledgments}

This program is partially supported by the Engineering Research Centers Program of the National Science Foundation under Award Number EEC-9986866. The major contributions to this paper, both as teachers and researchers, have come from the following TASEM members; Greg Wile, Jonathan Brown, Nathan Usher, Brandon Gregory, Gaurav Bhatnager, Yang Lu, Nelson Sepulveda-Alancastro and Shawn Aslam.

The author is also indebted to Ken Wise and Leo McAfee for continued support and encouragement of this program. In various TASEM sessions, the author highly appreciates the support of volunteers including Alice Wile, Sonya B., Zahida Aslam and Shawn Aslam.

\section{References}

1 American Association for the Advancement of Science, 1990; Bartel, Lichtenberg, \& Vaughan, 1992; Lipman, 1991; National Research Council, 1996).

2 Blumenfeld, P. C., Marx, R. W., Patrick, H., Krajcik, J. S., \& Soloway, E. (1997). Teaching for understanding. In B. J. Biddle, T. L. Good \& I. F. Goodson (Eds.), International handbook of teachers and teaching (pp. 819-878). The Netherlands: Kluwer Academic Publishers.

3 Lipman, M. (1991). Thinking in education.New York: Cambridge University Press.

4 CTGV. (1992). The jasper series as an example of anchored instruction: Theory, program description, and assessment data. Educational Psychologist, 27(3), 291-315.

5 Krajcik, J. S., Blumenfeld, P. C., Marx, R. W., Bass, K. M., Fredricks, J., \& Soloway, E. (1998). Inquiry in projectbased science classrooms: Initial attempts by middle school students. The Journal of the Learning Sciences, 7(3\&4), 313-350.

6 Penner, D. E., Lehrer, R., \& Schauble, L. (1998). From physical models to biomechanics: A design-based modeling approach. The Journal of the Learning Sciences, 7(3\&4), 429-449.

7 Songer, N.B. (1996). Exploring learning opportunities in coordinated networkenhanced classrooms: A case of kids as global scientists. Journal of the Learning Sciences, 5, 297-328.

8 D. Fortus, R.C. Dershimer, J. Krajcik, R.W. Marx and R. Mamlok-Naaman, design based science and student learning, J. Research Sci. Teaching, 41, 1081-1110 (2004).

9 Roberts, P. (1995). The place of design in technology education. In D. Layton (Ed.), Innovations in science and technology education (pp. 27-38). UNESCO.

10 Baynes, K. (1994). Designerly play. Loughborough, UK: Loughborough University of Technology.

11 Simon, H.A. (1999). The sciences of the artificial. Cambridge, MA: MIT Press.

12 Bucciarelli, L.L. (1994). Designing engineers. Cambridge, MA: MIT Press.

13 Davis, M., Hawley, P., McMullan, B., \& Spilka, G. (1997). Design as a catalyst for learning. Alexandria, VA: Association for Supervision and Curriculum Development.

14 ITEA. (2002). Standards for technological literacy. Reston, VA: International Technology Education Association.

15 NRC. (1996). National science education standards. Washington, DC: National Academy Press.

16 NRC. (2002). Scientific research in education. Washington, DC: National Academy Press. Penner, D.E., Lehrer, R., \& Schauble, L. (1998). From physical models to biomechanics: A design-based modeling approach. Journal of the Learning Sciences, 7, 429-449.

17 Chiapetta, E.L., Koballa, Jr., T.R., \& Collette, A.T. (2002). Science instruction in the middle and secondary schools (5th ed.) Upper Saddle River, NJ: Prentice-Hall.

18 Kolodner, J.L. (1993). Case-based reasoning. San Mateo, CA: Morgan Kaufmann.

19 Kolodner, J.L., Crismond, D., Gray, J., Holbrook, J.K., \& Puntambekar, S. (1998). Learning by design from theory to practice. Presented at the International Conference of the Learning Sciences, Georgia Tech University, Atlanta GA.

20 Barrows, H.S. (1985). How to design a problem-based curriculum for the preclinical years. New York: Springer.

21 Azuma R. A Survey of Augm.ented Reality. PRESENCE: Teleoperators and Virtual Environments, Vol. 6, No. 4, pp. 355-385, 1997.

22 Osberg K. Spatial Cognition in the Virtual Environ., Technical R-97-18. Seattle: Human Interface Technol. Lab, 1997.

23 Rizzo AA, Buckwalter JG, Neumann U, Kesselman C, Thiebaux M, Larson P, and van Rooyen A. The Virtual Reality 
Mental Rotation Spatial Skills Project. In CyberPsychology and Behavior, 1(2), pp. 113-120, 1998.

24 Pantelidis, V. S. Reasons to Use Virtual Reality in Education, VR in the Schools 1(1), 1995. URL: http://www.soe.ecu.edu/vr/reas.html (Revised 2000).

25 Roussos, M., Johnson, A., Moher, T., Leigh, J., Vasilakis, C., and Barnes, C. Learning and Building Together in an Immersive Virtual World. PRESENCE 8(3), pp. 247-263, MIT Press, June 1999.

26 Winn, W. A Conceptual Basis for Educational Applications of Virtual Reality, Technical Report TR 93-9: http://www.hitl.washington.edu/publications/r-93-9/, 1993.

27 Zagoranski, S. and Divjak, S., Use of augmented reality in education, EUROCON 2003, 2, 339-342.

28 D.M. Aslam, "Micro- and Nano- Technologies in K through Ph.D. Education and Research", Keynote, Second World Congress Biomimetics, Artificial Muscles and Nano-Bio (Nano-Bio 2004) Albuquerque, New Mexico, December 6-8, 2004.

29 D.M. Aslam, "Small Tech Education", Keynote, High Desert MNT Regional Workshop, TVI Workforce Training Center - Albuquerque, NM, October 12-13, 2004.

30 S. Wolf, "Microchip Manufacturing", Lattice Press, 2004.

31 H. Liu et al., "Characterization of the Ultrathin Vertical Channel CMOS Technology", IEEE Trans. Electron Dev., 51, 2004

32 Yu et al., "FinFET Scaling to 10nm Gate Length", IEEE 2004. 


\section{Appendix A}

Copyright by Michigan State University www.egr.msu.edu/ aslam

\section{Experiment \# 1: Measuring Distance}

Objectives: To measure distance using a Lego gear and a then using a programmable robot. Collect the distance data.

Materials:

- Computer with USB interface

- Robotics Invention System 2.0; Gearbot

- LEGO pieces to build the measuring wheel Introduction:

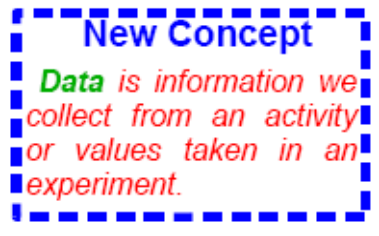

Fig. 1 A distance measuring wheel.

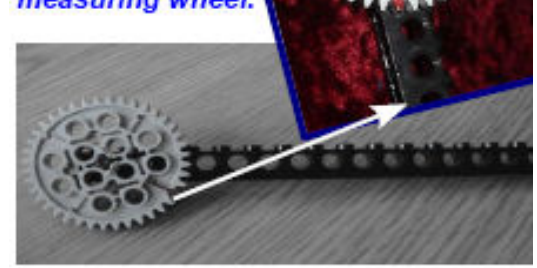

aspect of our universe. In fact, it is so common that you may hardly take notice of its significance in your everyday life. For example, how far is it from this end of the room to that end of the room? In other words, what is the distance between the two ends of the room? This experiment will allow you to measure the distance using first simple method and then using a robot.

\section{Procedure: How to measure the distance?}

1. Normally the distance is measured using a measuring tape. Let us use a

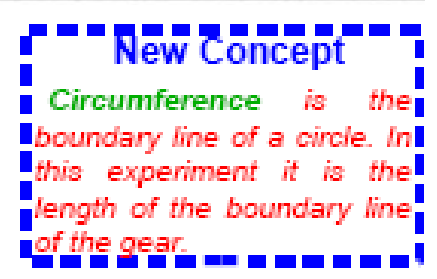
gear (attached to a rod), shown in Figure 1, to measure the distance. This gear has 40 teeth and one of these is marked with a red arrow. The red tooth acts as a starting point.

2. What distance is measured in one complete turn of the gear? As the gear completes one turn (revolution), the total distance, for a gear with 40 teeth, is 13.1 centimeters $(\mathrm{cm})$ as explained in Fig. 2. In science and mathematics, we call this circumference. Thus, the circumference of the 40 tooth gear is $13.1 \mathrm{~cm}$. This means that the distance measured by the wheel shown in Fig. 1 when it completes one revolution is $13.1 \mathrm{~cm}$. The distance for two complete revolutions will be $13.1+$ $13.1=26.2 \mathrm{~cm}$. You could also write it as

I.3.I times 2 which is equal to 26.2 cm. In mathematics, 1.3 .1 times $\mathbf{2}$ can also be written as $1.3 .1 \times \mathbf{2}$.

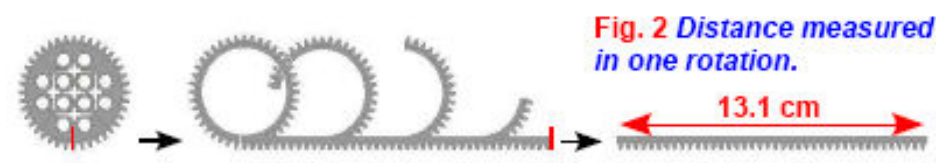

3. Because the distance that we measure depends on the number of revolutions of the wheel, we may call the distance a variable. Thus, a variable is something that is not constant because it changes or varies. In science, we use letters from the English alphabet to represent (or denote) a variable. Now suppose that the letter $\boldsymbol{d}$ represents the distance. Therefore, for two revolutions, the distance $\boldsymbol{d}$ can be written using an equation:

$\boldsymbol{d}=\boldsymbol{I . 3 . I}+1.3 .1 \mathrm{~cm} \ldots$... (I)

or one can also write:

$\boldsymbol{d}=1.3 .1 \times \mathbf{2} \mathrm{cm} \ldots . .(2)$

The equations (1) and (2) will give you the same answer.

Questions: Can you name other things (quantities) that are variables? Name the quantities that are constants? Can you write an equation?

4. Now you are ready to measure any distance using the wheel shown in Fig. 1. Just move the gear and count the number of revolutions (see Figure 3). If the number of revolutions is $\boldsymbol{n}$, then the total 
measured distance $\boldsymbol{d}$ is computed by the following equation:

$\boldsymbol{d}=1.3 .1$ times $\mathrm{n} \mathbf{c m}$

For example, if $n$ is 5 , then $d=13.1 \times 5=$

65.5 cm. Now use this method to collect data and enter in the table below.

\section{Let us mow consider some questions:}

(a)How do you find the distance if the number of revolutions is not a whole number (such as 1,

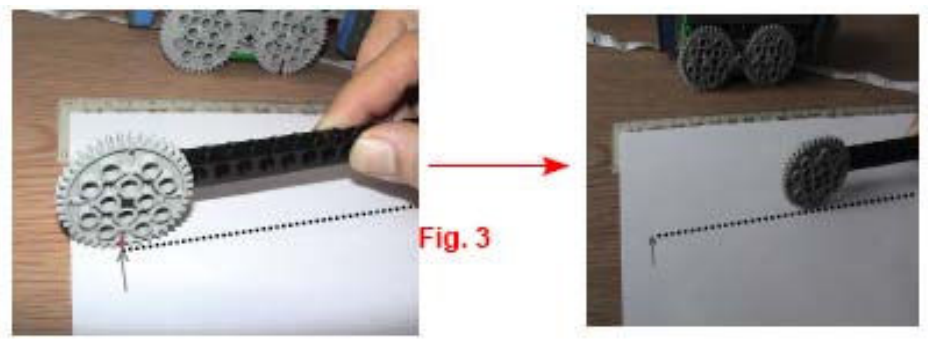

2,3 .. and so on) but a fractiom? (b)What is the distance covered when the gear moves through 20 teeth? (c)Find the total distance if you have one complete revolution and a half revolution of the wheel? (d)How accurate is this method of distance measurement?

\section{Use Gearbot}

5. Now let us measure the distance using the gear attached to the gearbot you built during the training sessions. Mark one of the teeth of the gearbot by using a red marker as shown in Figure 4.

6. Program the gearrobot to run at very slow speeds (so that you can count the revolutions) for a certain time such as 2 seconds (sec). Run it and count the number of revolutions. Find the distance for different speeds and run times of the

\begin{tabular}{|c|c|c|c|c|}
\hline \multicolumn{5}{|c|}{ Measured distances in $\mathrm{cm}$ or inches } \\
\hline Trials & Shoe & Table & Doorway & Gearbot \\
\hline Trial 1 & & & & \\
\hline Trial 2 & & & & \\
\hline Trial 3 & & & & \\
\hline
\end{tabular}
gearbot and complete the Table below.

7. Please note that in this experiment, you may have to consider a fraction of a revolution. Ask your teachers if you need help on fractions.

\section{Questions:}

1. Can you think of any other way of measuring distance using the RCX? For example, using light or touch sensors to measure distance.

2. Can you measure the distance traveled by a toy train or ball

\begin{tabular}{|l|l|l|l|l|}
\hline \multicolumn{6}{|c|}{ Gearbot: Measured distances in cm or inches } \\
\hline & $2 \mathrm{sec}$ & $4 \mathrm{sec}$ & $6 \mathrm{sec}$ & $10 \mathrm{sec}$ \\
\hline Trial 1 & & & & \\
\hline Trial 2 & & & & \\
\hline Trial 3 & & & & \\
\hline
\end{tabular}
using the RCX?

\section{Explore More:}

Would it not be cool if you do not have to count the number of revolution of the gear to measure distance? A rotation sensor, if attached to a gear can count the number of revolutions of the gear (or a wheel) and it can tell RCX to record this value. In the next experiment, you will learn how to use a rotation sensor with the gearbot and how to program the RCX to measure distance. In an other experiment, done later, we will use a rotation sensor and a light sensor to do Mars exploration!

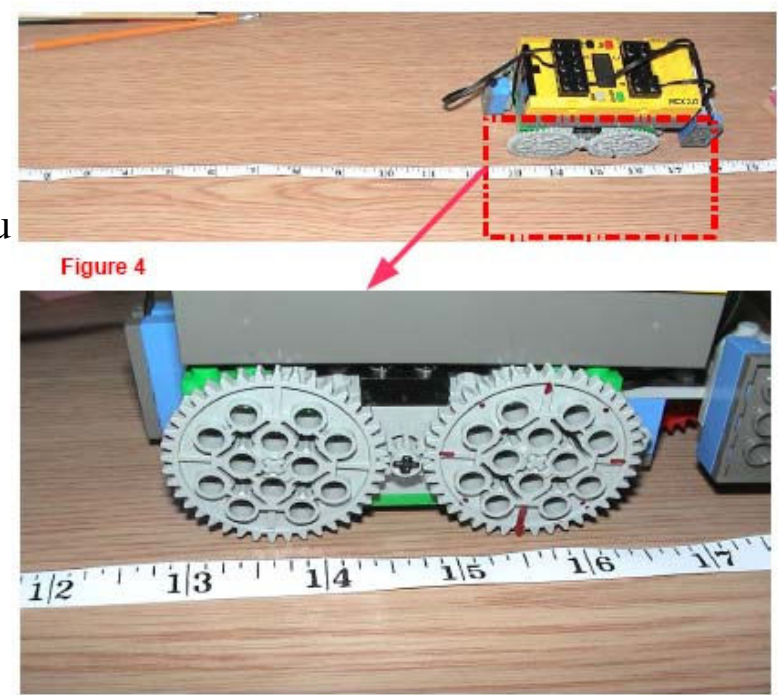




\section{Appendix B \\ Microcontroller Programming \\ Vers: 3.5 .06}

\section{Introduction}

A microcontroller ( $\mathrm{C}$ ), found in today's smart consumer products, is an inexpensive single chip computer. A state of the art $\mathrm{C}$ contains a central processing unit (CPU), random access memory (RAM), read only memory (ROM), input/output (I/O) lines, serial and parallel ports, and analog-todigital (A/D) and D/A converters. Some new C equipped with speech processing and rf interfaces. A number of companies produce $\mathrm{C}$ but those from Microchip, the so called $\mathrm{PIC}^{1}$ microcontrollers, are popular because they are fast and inexpensive ${ }^{2}$. High level languages such as $\mathrm{C}$ or BASIC can be used to program the PIC $\mathrm{C}$ if compilers for $\mathrm{C}$ or BASIC are used.

This document describes (i) programming of a $\mathrm{C}$ and (ii) application of $\mathrm{C}$ systems in education, especially pre-college education.

\section{Microcontroller Programming}

With the advancement of microfabrication techniques, which has led to system-on-chip (SOC) and wireless integrated microsystems (WIMS) ${ }^{3}$ technologies, the traditional boundaries between microelectronics, computer engineering and computer science seem to be fading. This has led to research, development and use of microcontrollerbased systems by professionals of different backgrounds. The ease of use of $\mathrm{C}$ programming kits and integrated development environment (IDE) supplied by a number of companies ${ }^{4}$ have resulted in a tremendous expansion of the use of microcontrollers by professionals of different educational backgrounds and skills.

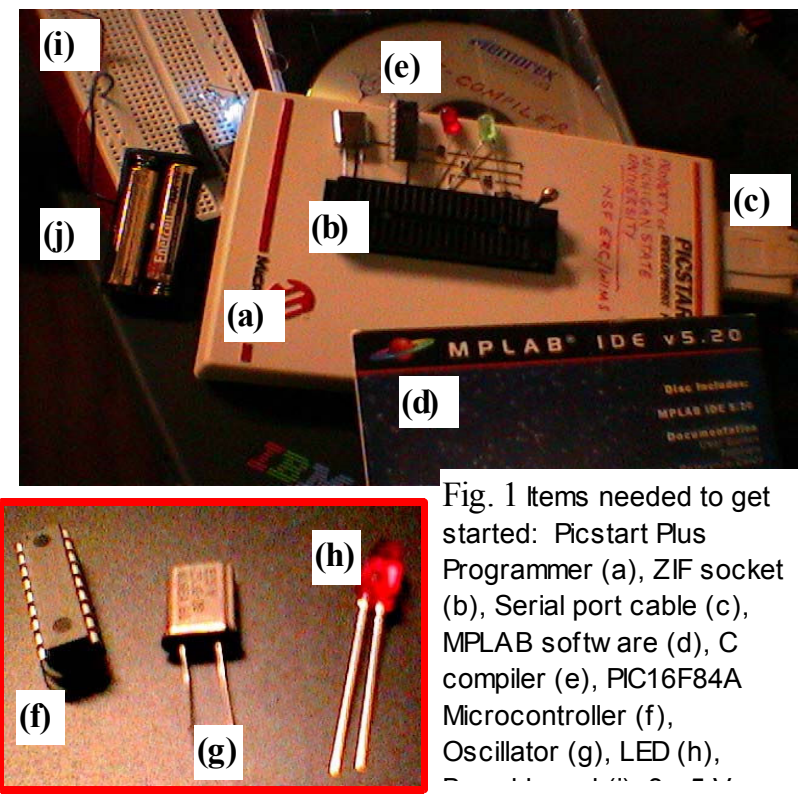

Perhaps for the first time, we have introduced microcontroller programming to pre-college students and teachers. An attempt is made to design the example below for use in a pre-college environment.

\subsection{Example 1}

It is assumed that you have some familiarity with programming in $\mathrm{C}$ or BASIC, and have the following items available to you (see Fig. 1):

- A computer with CD-ROM drive (Pentium 100 or better, running Win 95 or higher).

- Picstart Plus Programmer.

- MP Lab IDE software.

- Compiler software for C or BASIC.

- A bread board, light emitting diodes (LED), jumper wires, a crystal oscillator and a $5 \mathrm{~V}$ supply/battery. 


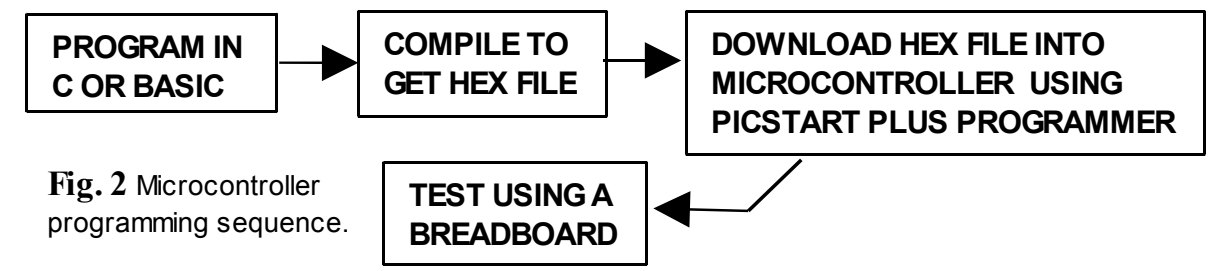

In this example, we use a

Fig. 2 Microcontroller very simple experiment to program a microcontroller. BREADBOARD

This will involve blinking the LEDs connected to a microcontroller. The objective of this experiment is to learn how to program a C. The overall procedure is depicted in Fig. 2. In the following section, we shall go through three important steps; (i) write a program and compile it to get a hex file, (ii) download the hex file into a PIC microcontroller using Pickstart Plus Programmer and (iii) test the microcontroller using a bread board:

\section{Program and Compile}

Let us write a program in $\mathrm{C}$. The program must be written for a certain type of microcontroller ( $\mathrm{C}$ ). We select PIC16F84 (or PIC16F84A) ${ }^{5}$ which is a very popular $\mathrm{C}$ with a wide range of operating voltages (3$5.5 \mathrm{~V})^{6}$.

In this example, the program will be written and compiled using a CCS compiler ${ }^{7}$. When you run the CCS compiler, you should get the CCS window on your PC screen as shown in Fig. 3(a):

(a)Click on File $>$ New to get the screen view shown in Fig. 3(b).

(b)Enter a file name (e.g., aslam1.C) and save it in a folder and write down the location of the folder on the C-drive of your PC (you can create a new folder at a location of your choice so that you can easily find it).

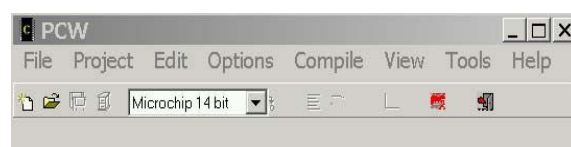

(c) If you are not sure or are new to C, copy the C code shown in Fig. 4. This program, written for PIC16F84, will blink the LEDs connected to ports $\mathbf{A 0}, \mathbf{A 1}$ and $\mathbf{A 2}$ of the microcontroller.

(d)After you have written the C code, click on Save in the File menu.

(e) Now you are ready to compile the $\mathrm{C}$ file (you just created) into a hex file. To do this, click on Compile in the Compile menu.

(f) If the compiler works without any errors you should see a screen similar to the one shown in Fig. 4.

(g)Your C program has been successfully compiled and the related hex file (e.g.,

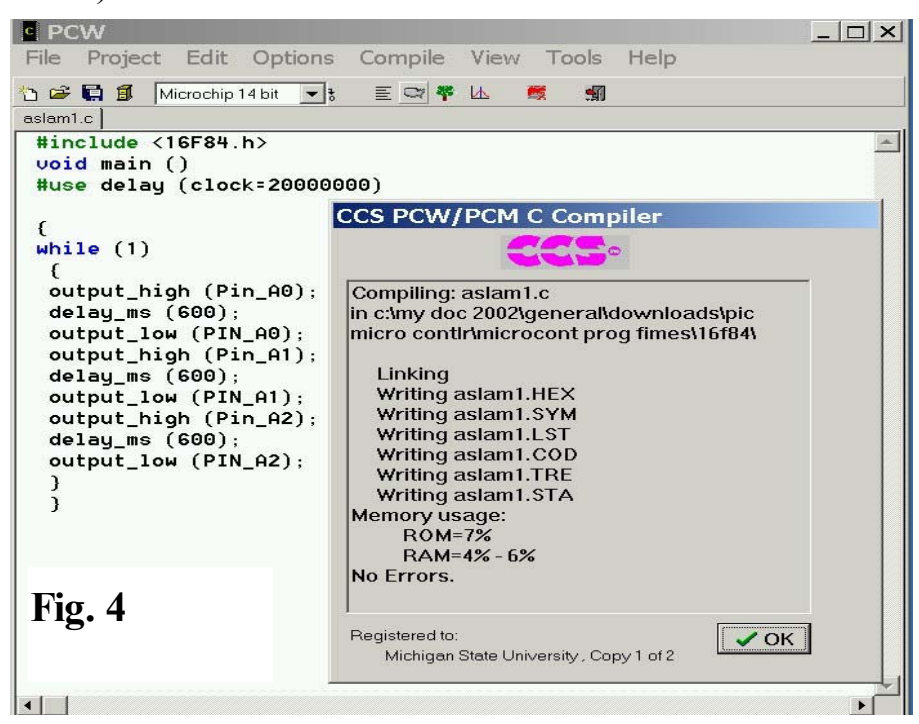

5 Another microcontroller, that has the same pin layout as PIC16F84 but does not require an external clock (oscillator), is PIC16F628.

6 If you use PIC16F84A, you take advantage of a free compiler for C that comes with MPLab's C Programming Kit and can be used only for PIC16F84A. However, it is recommended that you purchase the full version of the C compiler (CCS or Hitec).

7 The CCS compiler costs approximately $\$ 200-350$ depending upon the number of copies (see http://www.ccsinfo.com/). A free C Lite compiler 
aslam1.hex) is saved in the same folder where you saved the $\mathrm{C}$ file.

(h)If you face a problem with compiling, try closing compiler window, restarting the compiler and writing a new but simple $C$ program. In some cases, you may have to reboot the $P C$.

(i) You are now ready to down-load the hex file into PIC16F84.

\section{Down-load Hex File}

If the MPLab IDE software is not installed on your computer, install the software following the instructions that came with the software:

(a) Using a serial cable, connect the Picstart Plus Programmer to your PC, and then start the MPLab IDE software (version 6.5 or higher is needed).

(b)The first step is to select the programmer. Click on Programmer and then select Pickstart Plus as the programmer.

(c)Enable Programmer by first clicking on the Programmer tab.

(d)Now select the device (follow the black arrows in Fig. 5) by first clicking on the Configure tab. Make sure that you select the device you are using, which is PIC16F84.

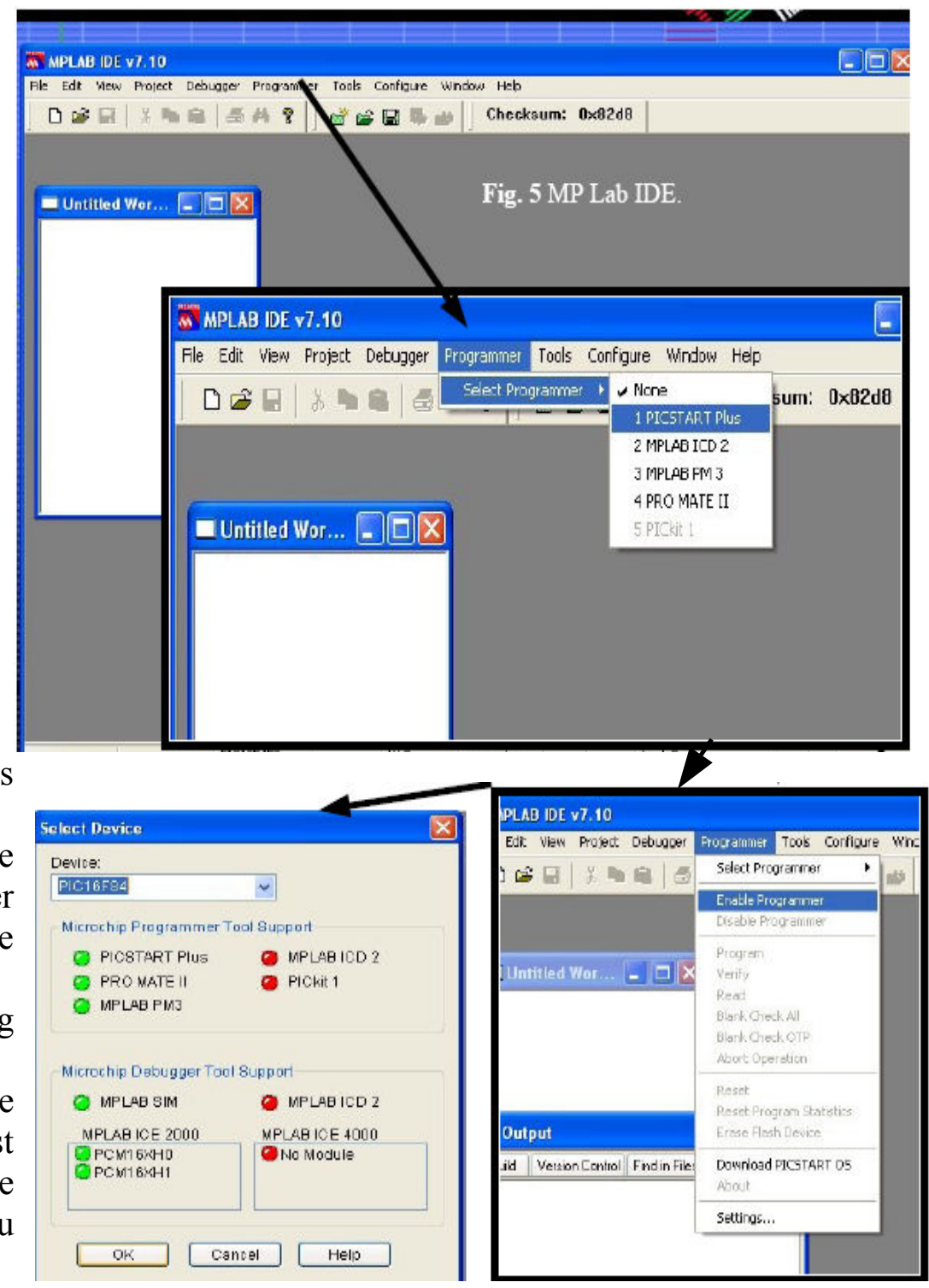

(e) Now to import the hex file you created above, click File $>$ Import to memory, and select the hex file (e.g., aslam1.hex) which is in the same directory where you saved the C file (e.g., aslam1.C) earlier.

(f) Now you can program the PIC16F84. Before you do this, insert a new PIC16F84 in the ZIF socket (see Fig. 1b) located on top of the Picstart-Plus Programmer.

(g)Click the Programmer tab in the MP Lab menu and then click on Program. You will see the progress near the bottom-left of the window (Fig. 6).

(h)After the programming is completed successfully (follow the black arrows in Fig. 6 to see the Output window), you are ready to test the PIC16F84 in a circuit.

(i) Remove the PIC16F84 from the ZIF socket of the programmer. You will need a white board called Breadboard, see Fig. 1(i), to complete the test circuit.

\section{Test}

The pin layout of PIC16F84 is shown in Fig. 7. If, using a breadboard, you make connections as shown in Fig. 7, the LEDs should blink every $0.6 \mathrm{sec}$. Fig. 7 also shows the actual circuit with blinking 
LEDs. If there is a problem check the circuit connections, the breadboard, crystal oscillator and microcontroller.
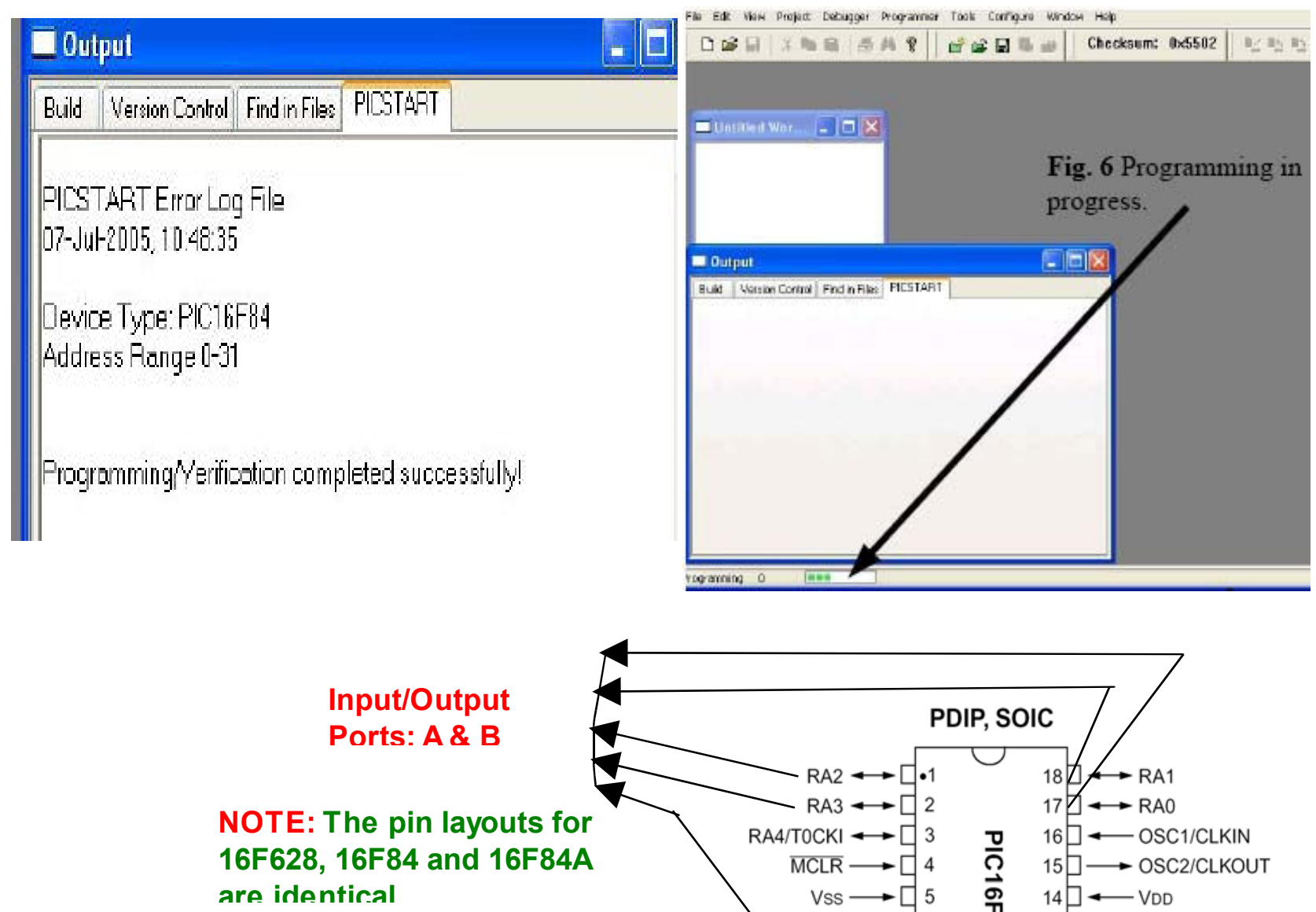

Fig. 7 Circuit connections for 18-pin PIC: See Figure below :
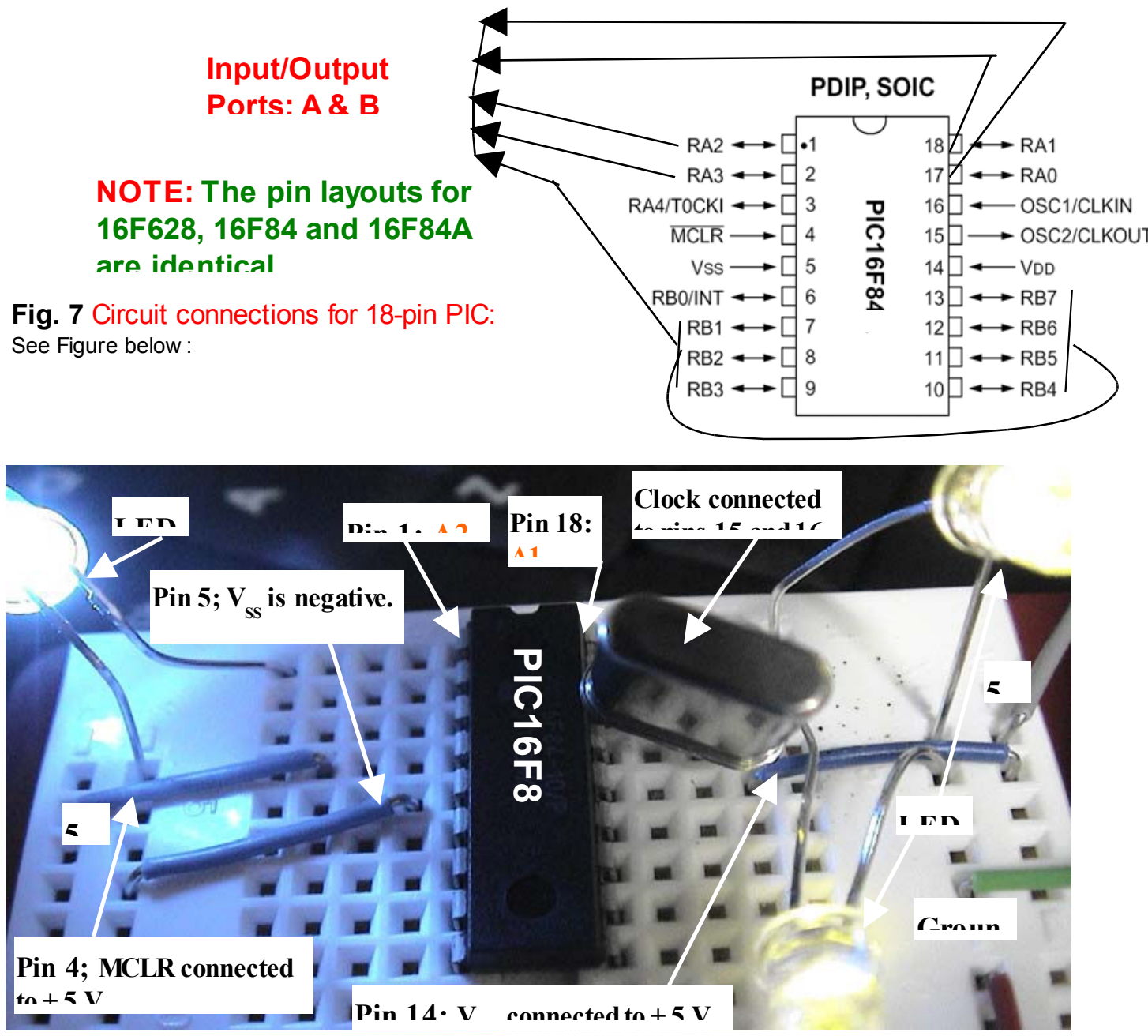